\title{
Acquired Fanconi syndrome in patients with Legionella pneumonia
}

\author{
Naoko Kinoshita-Katahashi ${ }^{\text {* }}$, Hirotaka Fukasawa', Sayaka Ishigaki', Shinsuke Isobe ${ }^{2}$, Shiro Imokawa ${ }^{3}$, \\ Yoshihide Fujigaki ${ }^{2}$ and Ryuichi Furuya ${ }^{1}$
}

\begin{abstract}
Background: Hyponatremia is often observed in patients with Legionella pneumonia. However, other electrolyte abnormalities are uncommon and the mechanism remains to be clarified.

Case presentation: We experienced two male cases of acquired Fanconi syndrome associated with Legionella pneumonia. The laboratory findings at admission showed hypophosphatemia, hypokalemia, hypouricemia and/or hyponatremia. In addition, they had the generalized dysfunction of the renal proximal tubules presenting decreased tubular reabsorption of phosphate (\%TRP), increased fractional excretion of potassium (FEK) and uric acid (FEUA), low-molecular-weight proteinuria, panaminoaciduria and glycosuria. Therefore, they were diagnosed as Fanconi syndrome. Treatment for Legionella pneumonia with antibiotics resulted in the improvement of all serum electrolyte abnormalities and normalization of the \%TRP, FEK, FEUA, low-molecular-weight proteinuria, panaminoaciduria and glycosuria, suggesting that Legionella pneumophila infection contributed to the pathophysiology of Fanconi syndrome.
\end{abstract}

Conclusion: To the best of our knowledge, this is the first report demonstrating Fanconi syndrome associated with Legionella pneumonia.

Keywords: Fanconi syndrome, Legionella pneumonia, Electrolyte abnormality

\section{Background}

Fanconi syndrome is a generalized dysfunction of the renal proximal tubules without primary glomerular involvement. It is typically characterized by variable degrees of phosphate, amino acids or glucose wasting by the proximal tubules. In addition, hypokalemia, hypouricemia, metabolic acidosis and low-molecular-weight proteinuria can be part of the clinical spectrum [1]. Acquired forms of Fanconi syndrome are caused by paraproteinemia, Sjögren syndrome, primary biliary cirrhosis (PBC) and drugs such as cisplatin [2-4]. However, infectious diseases have not been reported as a cause of Fanconi syndrome.

In this report, we present extremely rare cases of Legionella pneumonia complicated by Fanconi syndrome.

\footnotetext{
* Correspondence: knstnk1984@yahoo.co.jp

${ }^{1}$ Renal Division, Department of Internal Medicine, Iwata City Hospital, 512-3 Ohkubo, Iwata, Shizuoka, 438-8550, Japan

Full list of author information is available at the end of the article
}

\section{Case presentation}

\section{Patient 1}

A 75-year-old man was admitted to our hospital with fever and general malaise.

A physical examination at the time of admission showed a body temperature of $38.9^{\circ} \mathrm{C}$, blood pressure of $120 / 70 \mathrm{mmHg}$ and a pulse rate of 80 beats/min. Laboratory findings showed a white blood cell count of 13,400/ $\mathrm{mm}^{3}$ and C-reactive protein (CRP) of $23.7 \mathrm{mg} / \mathrm{dL}$. A chest computed tomography (CT)-scan showed a ground-glass appearance in the right middle and lower lobes. Because the urinary antigen test for Legionella pneumophila serotype 1 (BinaxNOW ${ }^{\circ}$ Legionella, Binax, Inc. ME, USA) was positive, he was diagnosed as Legionella pneumonia.

Several electrolyte abnormalities coexisted including hyponatremia, hypokalemia, hypophosphatemia and hypouricemia. His renal function was normal and the arterial blood gases analysis showed mild metabolic acidosis (Table 1). The tubular reabsorption of phosphate (\%TRP) was decreased, although the fractional excretion of uric acid (FEUA) was increased, indicating disturbed proximal

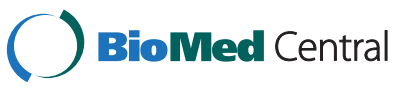


Table 1 Laboratory data on admission

\begin{tabular}{|c|c|c|c|}
\hline & Normal range & Patient 1 & Patient 2 \\
\hline BUN & $8-22 \mathrm{mg} / \mathrm{dL}$ & 17 & 41 \\
\hline Serum creatinine & $0.71-1.20 \mathrm{mg} / \mathrm{dL}$ & 0.88 & 2.23 \\
\hline Serum sodium & $136-147 \mathrm{mEq} / \mathrm{L}$ & 121 & 143 \\
\hline Serum potassium & $3.6-5.0 \mathrm{mEq} / \mathrm{L}$ & 3.4 & 3.5 \\
\hline Serum phosphorus & $2.5-4.3 \mathrm{mg} / \mathrm{dL}$ & 1.3 & 2.0 \\
\hline Serum uric acid & $<7.0 \mathrm{mg} / \mathrm{dL}$ & 2.4 & 2.7 \\
\hline Serum chloride & $101-109 \mathrm{mEq} / \mathrm{L}$ & 83 & 107 \\
\hline Serum CPK & 56-244 IU/L & 670 & 2,330 \\
\hline Bicarbonate & 22.0-26.0 mEq/L & 20.8 & 15.7 \\
\hline Anion gap & $12 \pm 2 \mathrm{mEq} / \mathrm{L}$ & 15.2 & 20.3 \\
\hline Serum osmolarity & 285-295 mOsm/kg & 255 & N.D. \\
\hline Urinary osmolarity & $\mathrm{mOsm} / \mathrm{kg}$ & 673 & N.D. \\
\hline ADH & $0.3-4.2 \mathrm{pg} / \mathrm{mL}$ & 1.7 & N.D. \\
\hline Proteinuria & Negative; (-) & $(2+)$ & $(2+)$ \\
\hline Leukocyturia & Negative; (-) & $(-)$ & $(-)$ \\
\hline Urinary $\mathrm{pH}$ & $4.8-7.5$ & 6.5 & 5.5 \\
\hline Urinary glucose & Negative; (-) & $(3+)$ & $(2+)$ \\
\hline Urinary RBC & $0-4 / \mathrm{HPF}$ & 10-19/HPF & 10-19/HPF \\
\hline$\% \mathrm{TRP}$ & $81-90 \%$ & 54.0 & 51.0 \\
\hline FEK & $10.0-20.0 \%$ & 18.4 & 33.1 \\
\hline FEUA & $5.5-11.0 \%$ & 18.7 & 42.8 \\
\hline$\beta 2-M G$ & $<250 \mu \mathrm{g} / \mathrm{L}$ & 80,397 & 110,556 \\
\hline NAG & $<7.0 \mathrm{U} / \mathrm{L}$ & 18.0 & 19.7 \\
\hline
\end{tabular}

Definition of the abbreviations: $A D H$ antidiuretic hormone, $B U N$ blood urea nitrogen, $C P K$ creatine phosphokinase, FEK fractional excretion of potassium, FEUA fractional excretion of uric acid, HPF high power field, NAG N-acetyl- $\beta-D-$ glucosaminidase, N.D. not determined, $R B C$ red blood cell, \%TRP tubular reabsorption of phosphate, $W B C$ white blood cell, $\beta 2-M G \beta 2$-microglobulin. Conversion factors for units: BUN in $\mathrm{mg} / \mathrm{dL}$ to $\mathrm{mmol} / \mathrm{L}, \times 0.357$, creatinine in $\mathrm{mg} /$ $\mathrm{dL}$ to $\mathrm{mmol} / \mathrm{L}, \times 88.4$, phosphorus in $\mathrm{mg} / \mathrm{dL}$ to $\mathrm{mmol} / \mathrm{L}, \times 0.3229$, uric acid in $\mathrm{mg} /$ $\mathrm{dL}$ to $\mu \mathrm{mol} / \mathrm{L}, \times 59.48$, and $\mathrm{ADH}$ in $\mathrm{pg} / \mathrm{mL}$ to $\mathrm{pmol} / \mathrm{L}, \times 0.923$. No conversion is necessary for sodium, potassium, chloride, CPK, bicarbonate, anion gap, and osmolarity.

tubular reabsorption. Despite the hypokalemia, his urinary potassium excretion was not suppressed. Elevations in urinary levels of $\beta 2$-microglobulin ( $\beta 2-\mathrm{MG}$ ) and $\mathrm{N}$-acetyl- $\beta$-Dglucosaminidase (NAG), glycosuria and panaminoaciduria were also observed (Tables 1 and 2). Therefore, he was diagnosed as Fanconi syndrome.

In addition, his urinary osmolarity was greater than his serum osmolarity and the level of antidiuretic hormone $(\mathrm{ADH})$ was improperly high for the indicated serum osmolarity. There was no sign of extracellular fluid volume depletion. Therefore, a diagnosis of the syndrome of inappropriate secretion of ADH (SIADH) was also made.

$\mathrm{He}$ was treated for Legionella pneumonia with pazufloxacin mesilate (PZFX) at $1,000 \mathrm{mg}$ per day. After treatment, his physical status recovered and his electrolyte abnormalities improved. Furthermore, his \%TRP,
FEUA, urinary $\beta 2-\mathrm{MG}$ and NAG normalized, and the panaminoaciduria became undetectable (Figure 1A).

\section{Patient 2}

A 57-year-old man was admitted to our hospital with fever and dysarthria.

A physical examination showed a body temperature of $39.1^{\circ} \mathrm{C}$, a blood pressure of $112 / 48 \mathrm{mmHg}$ and a pulse rate of 98 beats/min. Laboratory findings showed a white blood cell count of $6,100 / \mathrm{mm}^{3}$ and CRP of $46.7 \mathrm{mg} / \mathrm{dL}$. A chest CT scan showed a ground-glass appearance in the left upper and lower lobes. Because of the positive urinary antigen test, he was diagnosed as Legionella pneumonia.

Several electrolyte abnormalities coexisted including hypophosphatemia, hypokalemia and mild hypouricemia. The arterial blood gas analysis showed metabolic acidosis (Table 1). The \%TRP was decreased, although his fractional excretion of potassium (FEK) and FEUA were increased. Furthermore, his urinary $\beta 2-\mathrm{MG}$ and NAG were remarkably increased (Table 1). Glycosuria and aminoaciduria were also observed (Table 2). Therefore, a diagnosis of Fanconi syndrome was made. Although his renal function was deteriorated, post-renal obstructive nephropathy and congenital anomalies were ruled out by the finding of abdominal CT scan.

Treatment for Legionella pneumonia was started with PZFX at 1,000 mg per day. After treatment, his symptoms disappeared and his electrolyte abnormalities improved. In addition, his \%TRP, FEK, FEUA, urinary $\beta 2-\mathrm{MG}$ and NAG normalized, and the aminoaciduria became undetectable (Figure 1B).

\section{Conclusions}

Because the electrolyte abnormalities disappeared after treatment for Legionella pneumonia and there was no evidence of other causes of Fanconi syndrome, it is most likely that Fanconi syndrome was associated with Legionella pneumonia in our cases. This is the first report of acquired Fanconi syndrome caused by infectious diseases.

Hyponatremia is known as a relatively common electrolyte abnormality in patients with Legionella pneumonia [5]. The responsible mechanism of hyponatremia is thought to be SIADH. In accordance with this mechanism, the hyponatremia in Patient 1 was accompanied by improperly high levels of $\mathrm{ADH}$ and improved following the recovery from Legionella pneumonia.

However, other electrolyte abnormalities are uncommon in patients with Legionella pneumonia, and the precise mechanism remains to be clarified [5]. In our cases, the laboratory findings at admission also showed hypophosphatemia, hypokalemia and hypouricemia. In addition, remarkably increased urinary excretion of low- 
Table 2 Data of the analysis of urinary amino acids on admission

\begin{tabular}{|c|c|c|c|}
\hline & Normal range (mmol/day) & Patient 1 & Patient 2 \\
\hline Taurine & $322.2-5214.5$ & 1318.6 & 272.5 \\
\hline Phosphoethanolamine & $31.0-110.0$ & 49 & 34.4 \\
\hline Urea & $130.3-493.2$ & 223.9 & 341.3 \\
\hline Aspartic acid & $<12.7$ & N.D. & 6.1 \\
\hline Hydroxyproline & N.D. & N.D. & N.D. \\
\hline Threonine & $79.9-528.3$ & 1530.2 & 380.7 \\
\hline Serine & $208.8-1020.0$ & 1529.6 & 478.3 \\
\hline Asparagine & $60.7-372.3$ & 747.4 & 393.6 \\
\hline Glutamic acid & $11.3-42.7$ & 30.1 & 15.5 \\
\hline Glutamine & $207.0-1357.3$ & 1071.2 & 170.3 \\
\hline Sarcosine & $<99.0$ & 24.8 & N.D. \\
\hline a-Aminoadipic acid & $16.7-118.6$ & 52.4 & 34.4 \\
\hline Proline & N.D. & 18.4 & 25.6 \\
\hline Glycine & $652.1-3670.6$ & 852.4 & 336.2 \\
\hline Alanine & $141.2-833.9$ & 839.3 & 538.6 \\
\hline Citrulline & $13.5-55.6$ & 63.4 & N.D. \\
\hline a-Aminobutylic acid & $<27.1$ & N.D. & N.D. \\
\hline Valine & $24.8-82.2$ & 97 & 104.2 \\
\hline Cystine & $23.7-170.9$ & 226.2 & 101.3 \\
\hline Cystathionine & $<44.7$ & 21 & $\underline{334.6}$ \\
\hline Methionine & $<20.2$ & 11.5 & 15.5 \\
\hline Isoleucine & $7.5-23.5$ & $\underline{26.5}$ & 29.2 \\
\hline Leucine & $24.6-89.3$ & $\underline{95.5}$ & $\underline{96.3}$ \\
\hline Tyrosine & $50.6-308.4$ & 327.4 & 111.8 \\
\hline Phenylalanine & $27.2-110.2$ & 150.7 & $\underline{199.8}$ \\
\hline Y-Amino $\beta$-hydroxybutyric acid & N.D. & N.D. & N.D. \\
\hline$\beta$-Alanine & $<153.0$ & 58.4 & 9.4 \\
\hline$\beta$-Amino-iso-butyric acid & $<1623.9$ & 151.8 & 288.5 \\
\hline$\gamma$-Aminobutyric acid & N.D. & N.D. & N.D. \\
\hline Monoethanolamine & $195.3-606.2$ & 292.8 & 356.8 \\
\hline Homocystine & N.D. & N.D. & N.D. \\
\hline Histidine & $436.4-2786.5$ & 1392 & 496.8 \\
\hline 3-Methylhistidine & $113.4-480.9$ & 202.9 & 396 \\
\hline 1-Methylhistidine & $59.3-2816.2$ & 821.2 & 16.7 \\
\hline Carnosine & $<87.6$ & N.D. & 21.2 \\
\hline Anserine & $<231.4$ & 49.4 & N.D. \\
\hline Tryptophan & $20.7-150.7$ & 156.7 & 59.2 \\
\hline Hydroxylysine & $<22.9$ & 3.8 & N.D. \\
\hline Ornithine & $6.9-43.9$ & 46.3 & 151.4 \\
\hline Lysine & 51.6-1639.6 & 794.9 & 148.1 \\
\hline Arginine & $11.6-54.8$ & 51.5 & 31.3 \\
\hline
\end{tabular}

Underlining indicates an abnormal value. N.D. means not detected. 


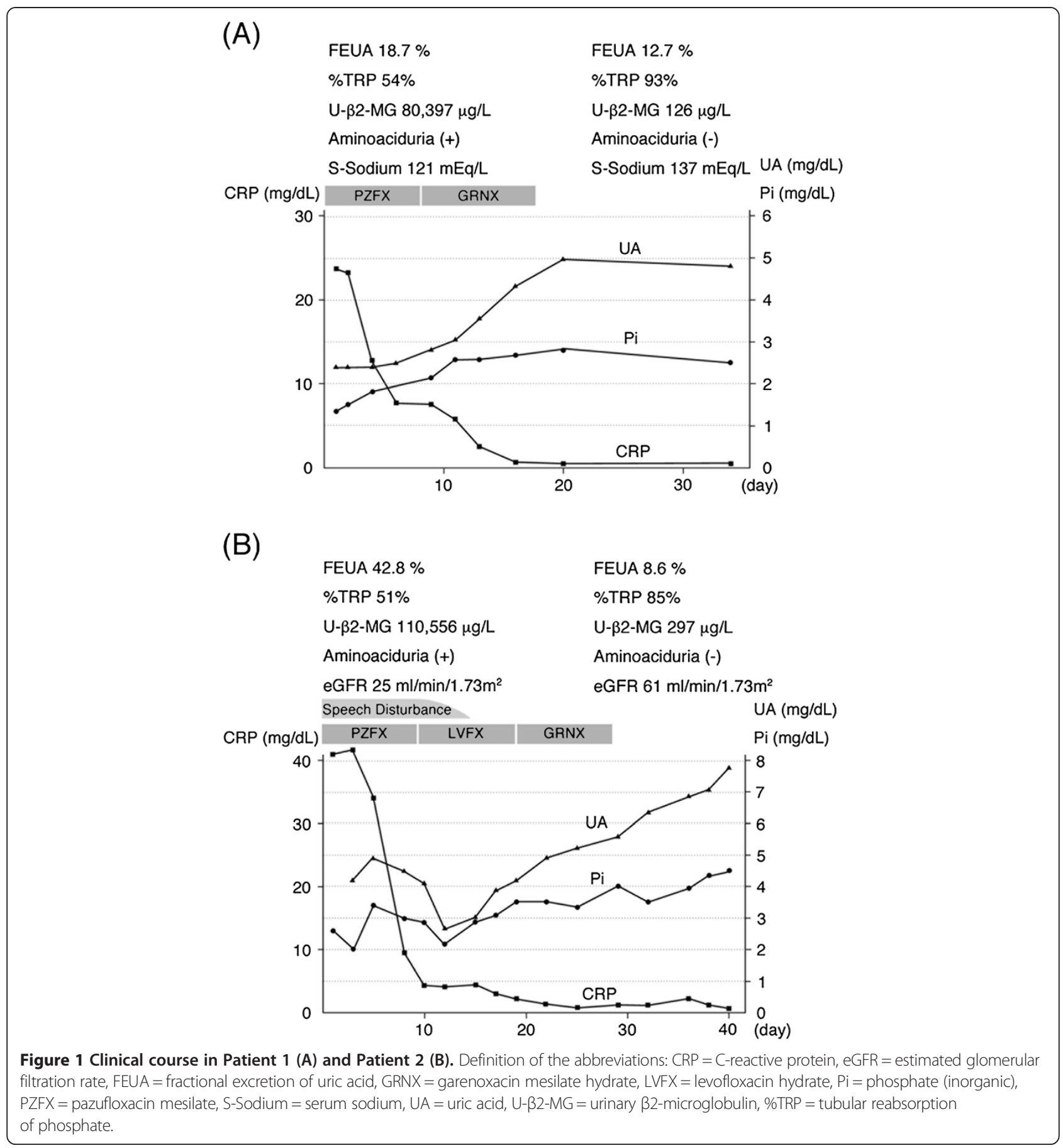

molecular-weight proteins such as $\beta 2$-MG, decreased \%TRP, increased FEK and FEUA, panaminoaciduria and glycosuria were coexisted. Therefore, our cases suggest that the proximal tubular dysfunction caused these serum electrolyte abnormalities.

A relationship has recently been proposed between mitochondrial disorders and Fanconi syndrome [6,7]. For instance, it is known that patients with mitochondrial disorders, including mitochondrial encephalomyopathy, lactic acidosis, and stroke-like episodes (MELAS), KearnsSayre syndrome, and anti-mitochondrial M2 antibodypositive primary biliary cirrhosis ( $\mathrm{PBC})$, often complicate with Fanconi syndrome $[4,8,9]$. Moreover, Fanconi syndrome related to antiviral agents, such as cidofovir, is thought to be caused by mitochondrial toxicity [10]. Because the mitochondria play a critical role in generating adenosine triphosphate (ATP) through oxidative phosphorylation and tubular epithelial cells, particularly in the 
renal proximal tubules, require a high energy supply from the mitochondria, it is reasonable that mitochondrial disorders can cause Fanconi syndrome. Interestingly, Evans et al. have reported that Legionella pneumophila, which is a facultative intracellular bacterium, was found inside renal tubular cells in autopsy cases of Legionella pneumonia [11]. In addition, it has been reported that Legionella pneumophila infection affects mitochondrial functions in mammalian cells $[12,13]$. Therefore, Legionella pneumophila infected the proximal tubular cells might interfere with their mitochondria and finally cause Fanconi syndrome in our cases.

However, we cannot explain the following issues: (i) from where Legionella pneumophila entered inside the renal proximal tubular cells (from basolateral or apical) and (ii) why the reabsorption defects developed only in the proximal tubules, not in the distal tubules. Furthermore, we cannot rule out the possibility that acute tubulointerstitial nephritis was occurred in the setting of Legionella pneumonia [14], although this possibility should be low because of the absence of typical symptoms such as rash and leukocyturia in our cases.

In summary, we experienced two rare cases of Legionella pneumonia complicated with Fanconi syndrome. Further studies are required to clarify the precise mechanisms responsible for the association between Legionella pneumophila infection and Fanconi syndrome.

\section{Consent}

Written informed consents were obtained from the patients for publication of this Case report and any accompanying images. Copies of the written consents are available for review by the Series Editor of this journal.
Received: 18 February 2013 Accepted: 9 May 2013

Published: 2 August 2013

\section{References}

1. Gaboardi F, Case L, Edefonti A, De Vecchi A, Graziani G: [Fanconi syndrome]. Minerva Med 1979, 70:3075-3083.

2. Maldonado JE, Velosa JA, Kyle RA, Wagoner RD, Holley KE, Salassa RM: Fanconi syndrome in adults. A manifestation of a latent form of myeloma. Am J Med 1975, 58:354-364.

3. Cachat F, Nenadov-Beck M, Guignard JP: Occurrence of an acute Fanconi syndrome following cisplatin chemotherapy. Medical and Pediatric Oncology 1998, 31:40-41.

4. Lino M, Binaut R, Noel LH, Patey N, Rustin P, Daniel L, Serpaggi J, Varaut A, Vanhille $P$, Knebelmann $B$, et al: Tubulointerstitial nephritis and Fanconi syndrome in primary biliary cirrhosis. Am J Kidney Dis 2005, 46:e41-46.

5. Yu VL, Kroboth FJ, Shonnard J, Brown A, McDearman S, Magnussen M: Legionnaires' disease: new clinical perspective from a prospective pneumonia study. Am J Med 1982, 73:357-361.

6. Niaudet P: Mitochondrial disorders and the kidney. Arch Dis Child 1998, 78:387-390

7. Emma F, Bertini E, Salviati L, Montini G: Renal involvement in mitochondrial cytopathies. Pediatr Nephrol 2012, 27:539-550.

8. Niaudet $P$, Rotig A: The kidney in mitochondrial cytopathies. Kidney Int 1997, 51:1000-1007

9. Campos Y, Garcia-Silva T, Barrionuevo CR, Cabello A, Muley R, Arenas J: Mitochondrial DNA deletion in a patient with mitochondrial myopathy, lactic acidosis, and stroke-like episodes (MELAS) and Fanconi's syndrome. Pediatr Neurol 1995, 13:69-72.

10. Izzedine H, Launay-Vacher V, Isnard-Bagnis C, Deray G: Drug-induced Fanconi's syndrome. Am J Kidney Dis 2003, 41:292-309.

11. Evans CP, Winn WC Jr: Extrathoracic localization of Legionella pneumophila in Legionnaires' pneumonia. Am J Clin Pathol 1981, 76:813-815.

12. Zhang C, Kuspa A: Transcriptional down-regulation and rRNA cleavage in Dictyostelium discoideum mitochondria during Legionella pneumophila infection. PLoS One 2009, 4:e5706.

13. Chong A, Lima CA, Allan DS, Nasrallah GK, Garduno RA: The purified and recombinant Legionella pneumophila chaperonin alters mitochondrial trafficking and microfilament organization. Infect Immun 2009, 77:4724-4739.

14. Nishitarumizu K, Tokuda Y, Uehara H, Taira M, Taira K: Tubulointerstitial nephritis associated with Legionnaires' disease. Intern Med 2000, 39:150-153.

doi:10.1186/1471-2369-14-171

Cite this article as: Kinoshita-Katahashi et al:: Acquired Fanconi syndrome in patients with Legionella pneumonia. BMC Nephrology 2013 14:171.

\begin{abstract}
Abbreviations
ADH: Antidiuretic hormone; ATP: Adenosine triphosphate; BUN: Blood urea nitrogen; CRP: C-reactive protein; CT: Computed tomography; FEK: Fractional excretion of potassium; FEUA: Fractional excretion of uric acid; GRNX: Garenoxacin mesilate hydrate; LVFX: Levofloxacin hydrate; MELAS: Mitochondrial encephalomyopathy, lactic acidosis, and stroke-like episodes; NAG: N-acetyl- $\beta$-D-glucosaminidase; PBC: Primary biliary cirrhosis; PZFX: Pazufloxacin mesilate; SIADH: Syndrome of inappropriate ADH secretion; S-Sodium: Serum sodium; \%TRP: Tubular reabsorption of phosphate; UA: Uric acid; $\beta 2-M G$ : $\beta 2$-microglobulin.
\end{abstract}

\section{Competing interests}

The authors declare that they have no competing interests.

\section{Authors' contributions}

NK, Sal, Shinl and Shirl treated the patient. NK wrote the first draft, and also evaluated the data. HF, RF and YF wrote the final draft. All authors reviewed and approved the final version of this manuscript.

\section{Author details}

${ }^{1}$ Renal Division, Department of Internal Medicine, Iwata City Hospital, 512-3 Ohkubo, Iwata, Shizuoka, 438-8550, Japan. ${ }^{2}$ Internal Medicine1, Hamamatsu University School of Medicine, 1-20-1 Handayama, Higashi-ku, Hamamatsu, Shizuoka 431-3192, Japan. ${ }^{3}$ Department of Respiratory Medicine, Iwata City Hospital, 512-3 Ohkubo, Iwata, Shizuoka 438-8550, Japan.

\section{Submit your next manuscript to BioMed Central and take full advantage of:}

- Convenient online submission

- Thorough peer review

- No space constraints or color figure charges

- Immediate publication on acceptance

- Inclusion in PubMed, CAS, Scopus and Google Scholar

- Research which is freely available for redistribution 